\title{
Standardized Indices of Mortality among Persons with Spinal Cord Injury: Accelerated Aging Process
}

\author{
Kaori IMAI ${ }^{1 *}$, Takehiro KADOWAKI ${ }^{2}$ and Yoshiharu AIZAWA ${ }^{3}$ \\ ${ }^{1}$ School of Health Sciences, Gunma University, 3-39-15 Showa-Machi, Maebashi, Gunma 371-8514, Japan \\ ${ }^{2}$ School of Allied Health Sciences, Kitasato University, 1-15-1 Kitasato, Kanagawa 228-8555, Japan \\ ${ }^{3}$ School of Medicine, Kitasato University, 1-15-1 Kitasato, Kanagawa 228-8555, Japan
}

Received July 30, 2001 and accepted December 24, 2003

\begin{abstract}
We conducted this study to compare survival rates and morbidity of persons with spinal cord injury (SCI) versus general population, and to clarify the risk of SCI persons. The subjects of this study were 960 men with SCI who had been accommodated in the eight Labor Accident Rehabilitation Centers in Japan during the period of 1965-1995. The surveyed items were the year of birth, the year of injury, level of spinal cord injury and survival status. The classification of cause of death was taken from ICD-10. The cumulative survival rate by life table method was calculated. In order to compare the risks of each cause of death in SCI persons with general population, causespecific standardized mortality ratio (SMR) was examined. The leading cause of death was malignant neoplasms at 28 persons, and SMR (general population=100) was 184 , followed by the circulatory system disease, external cause (including suicide) and the genitourinary system disease. In the subgroups of malignant neoplasms, the SMR was 6,619 for cutaneous carcinomas and 1,482 for bladder carcinomas $(\mathbf{p}<0.01)$. Thus aging-related diseases which had close correlation with lifestyle and environment were the major cause of deaths in SCI persons.
\end{abstract}

Key words: Spinal cord injury, Mortality, Cutaneous carcinoma, Bladder carcinoma, Heart disease, Suicide

\section{Introduction}

Health management of persons with spinal cord injury (SCI) improved dramatically in the last several decades. In the past, representative complications of the spinal cord injury were decubitus and urinary tract infection, and death by renal failure was the primary cause of death in paraplegics. The improvement of bladder control such as intermittent aseptic catheterization in acute phase, and self-catheterization in chronic phase ${ }^{1-4)}$ had resulted in a decrease of such complications as urinary tract infections, hydronephrosis and renal failure. Recently, it is suggested that circulatory diseases caused by arteriosclerosis and diabetes mellitus have been increasing among paraplegics ${ }^{5-12)}$. Also though data collected during clinical case studies suggested that SCI persons were at higher risk of contracting bladder and

\footnotetext{
*To whom correspondence should be addressed.
}

cutaneous carcinoma ${ }^{13)}$, there were no established studies which compared the mortality rate of the SCI persons with the general population. We conducted this study in order to compare the survival rates and the mortality of long-term SCI persons versus general population, and to clarify the risks of complicated diseases on SCI.

\section{Methods}

Subjects: The subjects of this study were 960 men with SCI from labor accidents, who were accommodated in eight Labor Accident Rehabilitation Centers in Japan during the period of 1965-1995. The objective of the centers is to help persons resume their works and social life, and to find a new work. Subjects are provided with some income for work $(2-5 \mathrm{~h} / \mathrm{d})$ from the centers. Many live in dormitories where meals are provided, although some live at home. In the time of investigation, residents in the centers were 247 
persons. They can carry on their daily lives, using wheel chairs at and away from work. The number of females with SCI by labor accident was too small for accurate statistical analysis, so females were excluded from the study.

\section{Survey Procedure}

\section{Survival data analysis}

The year of birth, the year of injury, period of residency in the Workshops, level of spinal cord injury and survival status were investigated. In cases of death, the date and cause of deaths were surveyed from the charts of the Workshops. The classification of cause of death was used according to the 10th International Classification of Disease $(\mathrm{ICD}-10)^{14)}$.

\section{Calculation}

The survival rate analysis was determined for 960 persons with SCI. The cumulative survival rate by life table method was calculated using PC SAS version 6.11 (Proc Lifetest). Comparison was made with normal population statistics using the 1995 life table of the general population in Japan ${ }^{15}$. The start of the observation of each subject with SCI was the initial time of residency in the Workshops. The effects of age at time of injury and severity of injury were examined as the affecting factors on survival time. Proportional-hazards regression analysis was used to identify items having a statistically significant effect ${ }^{16}$. Additional stratified lifetable analysis was carried out based on the proportionalhazards regression analysis findings. Significance was calculated using a log rank test.

\section{Cause-specific standardized mortality ratio}

In order to compare the risks of each cause of death on SCI persons with general population, standardized mortality ratio (SMR) was examined. SMR was calculated to divide actual mortalities of persons with SCI by the expected mortality of the general population. The standard death rates were based on the vital statistics 1995 of general population of Japan ${ }^{17)}$. The significance of SMR was examined by applying normal distribution, but in case of a subject group with less than 10 persons, a probability test based on the Poisson distribution was carried out.

\section{Results}

\section{Background of the subjects}

The distribution of type of SCI and age at injury was presented in Table 1. The average age of injury was 30.1
Table 1. The distribution of type of spinal cord injury and age at injury

\begin{tabular}{lcc}
\hline level of injury & number of subjects & percent $(\%)$ \\
\hline C-T5 & 93 & 9.7 \\
T6-T10 & 112 & 11.7 \\
T11-L1 & 637 & 66.3 \\
L2- & 72 & 7.5 \\
Undetermined & 46 & 4.8 \\
\hline Total & 960 & 100 \\
\hline
\end{tabular}

C: cervical vertebra, T: thoracic vertebra, L: lumbar vertebra.

\begin{tabular}{lcc}
\hline age at injury & number of subjects & percent $(\%)$ \\
\hline $15-19$ years old & 91 & 9.5 \\
$20-29$ & 422 & 44.0 \\
$30-39$ & 284 & 29.6 \\
$40-49$ & 131 & 13.6 \\
$50-59$ & 33 & 3.4 \\
\hline Total & 960 & 100 \\
\hline
\end{tabular}

and standard deviation (SD) was 9.2 yr old, the average age of initial entry into the centers was 36.9 ( $\mathrm{SD}=10.1) \mathrm{yr}$ old. Total fatalities were 118, and average age of death was 54.6 $(\mathrm{SD}=10) \mathrm{yr}$ old. Average duration from the time of injury to entrance into the centers was $6.8 \mathrm{yr}$, so the cumulative survival rate of persons with SCI who exceeded the average of $6.8 \mathrm{yr}$ after injury was calculated.

\section{Cumulative survival analysis}

The age at injury was classified by $10 \mathrm{yr}$ into five age groups (injury cohort). Figure 1 presents survival rates at each age for SCI by injury cohort. When benchmark age for comparison was set at $70 \mathrm{yr}$ of age, the survival rate for the injury cohort of twenties showed $30 \%$. Meanwhile survival rate for the general population was $75 \%$, then calculated difference was $45 \%$. The difference indicates the excess death due to SCI. Figure 2 showed survival rates at years after injury by injury cohort. Survival rates for injury cohorts of forties and fifties were lower than the younger injury cohorts at same age by log rank test $(\mathrm{p}<0.05)$. Regarding the site of injury, rates for each of the 5 groups of SCI persons presented similar values resulting in no appreciable differences between the groups.

\section{Mortality and Cause Specific Standardized Mortality Ratio} (SMR)

To compare with the mortality of general population, a SMR (general population=100) was calculated (Table 2). 


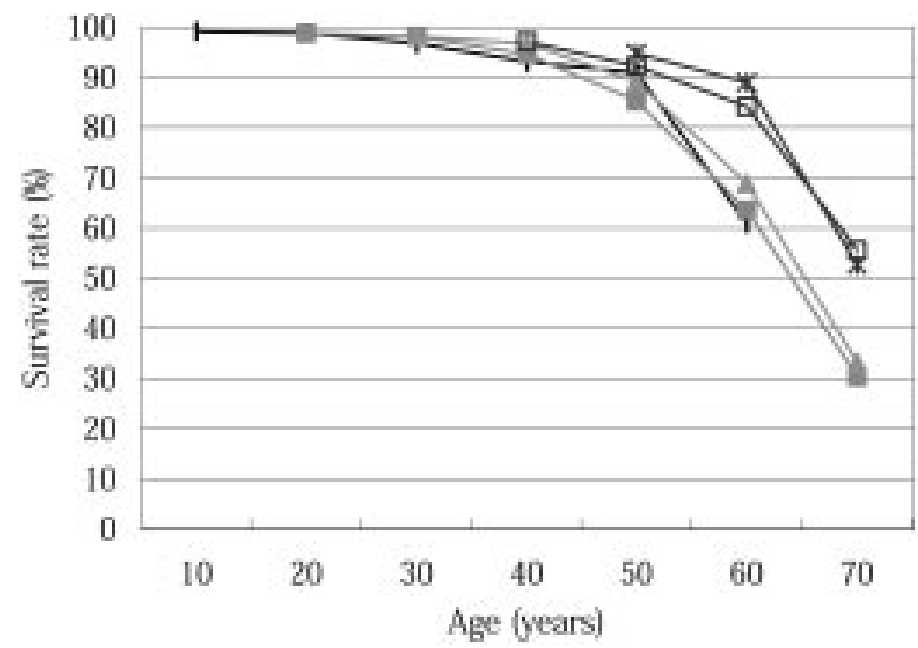

Age at injury

(injury cohort'

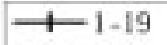

$-10-20-29$

$-4-30-39$

七- $40-49$

$\rightarrow-50-59$

Fig. 1. Survival rates at each age for SCI males by injury cohort.

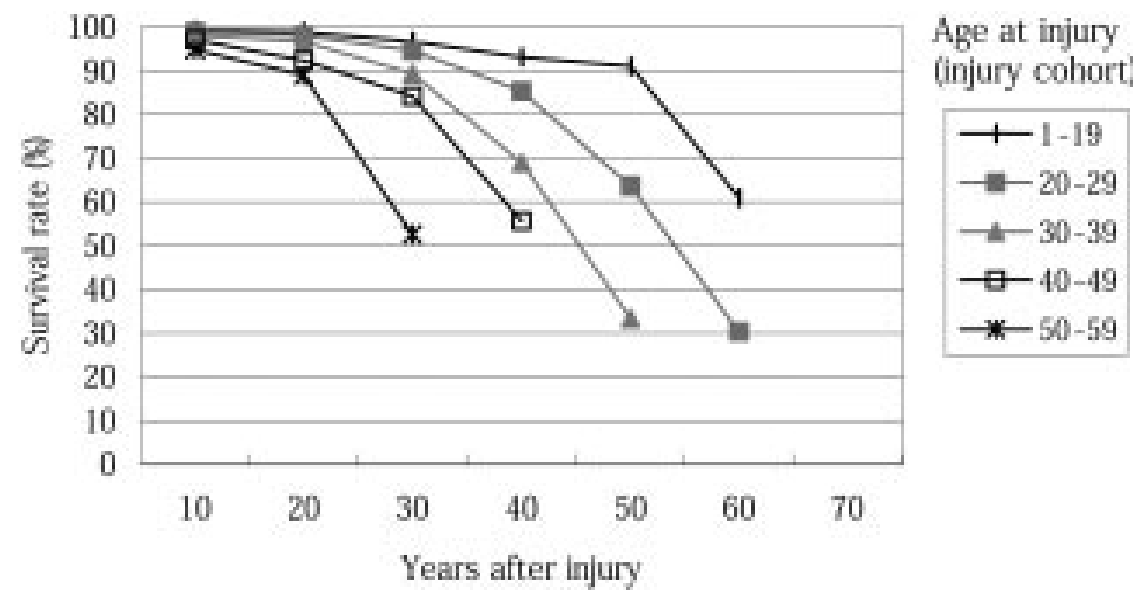

Fig. 2. Survival rates for SCI males by years after injury by injury cohort.

The SMR of total mortality showed 280, which means the total mortality is 2.8 times higher than the general population. The leading cause of death according to major classification of the ICD10 was neoplasms in 28 persons ( $\mathrm{SMR}=184)$, followed by circulatory system disease (258), external cause (291), disease of genitourinary system $(3,920)$, certain infectious and parasitic disease $(1,288)$. The SMRs according to detailed classification were 249 at heart diseases and 513 at suicide. In complications of SCI, SMR showed extremely high figures, such as 6,827 for septicemia that was mainly a result of decubitus, because the value of general population was small. Also the SMR of renal failure showed 3,739. All of the above SMRs were significant at the $1 \%$ level.

In the subgroups of malignant neoplasms, the SMR was 6,619 for cutaneous carcinomas and 1,482 for bladder carcinomas, which were recognized as significant at the $1 \%$ level by a probability test based on Poisson distribution (Table 3). All 3 cases of cutaneous carcinoma were described as generating from decubitus. Liver carcinoma was the prominent cause of neoplasm mortality and the SMR presented $251(\mathrm{p}<0.05)$.

\section{Discussion}

We have considered that long-term SCI accelerates the aging process, especially the prognosis of vascular disease resulting from arteriosclerosis, and some kind of malignant neoplasms. As Menter ${ }^{18)}$ described that SCI is one form of instant aging: persons with SCI might become vulnerable to further injury in multi-systems. In our study, the SMR of total death in long-term SCI was 2.8 times higher than general population $(\mathrm{p}<0.01)$. Regarding the survival rate by age at 
Table 2. Standardized Mortality Ratio (SMR) by causes of death in patients with spinal cord injury for a long time

\begin{tabular}{|c|c|c|c|}
\hline $\begin{array}{l}\text { ICD } \\
\text { code }\end{array}$ & $\begin{array}{l}\text { causes of death based on international } \\
\text { classification of diseases (10th revision) }\end{array}$ & $\begin{array}{c}\text { number of } \\
\text { death }\end{array}$ & SMR \\
\hline 02000 & neoplasms & 28 & $184 * *$ \\
\hline 02100 & malignant neoplasms & 26 & $175 * *$ \\
\hline 09000 & diseases of the circulatory system & 24 & $258 * *$ \\
\hline 09200 & heart diseases & 12 & $249 * *$ \\
\hline 09300 & cerebrovascular diseases & 12 & $301 * *$ \\
\hline 20000 & death by external causes & 18 & $291 * *$ \\
\hline 20101 & traffic accident & 4 & 126 \\
\hline 20200 & suicide & 14 & $513 * *$ \\
\hline 14000 & diseases of the genitourinary system & 15 & $3920 * *$ \\
\hline 14200 & renal failure & 13 & $3739 * *$ \\
\hline 01000 & infectious or parasitic diseases & 12 & $1288 * *$ \\
\hline 01300 & septicemia & 10 & $6827 * *$ \\
\hline 10000 & diseases of the respiratory system & 6 & $269 *$ \\
\hline 10200 & pneumonia & 2 & 176 \\
\hline 11000 & diseases of the digestive system & 5 & 189 \\
\hline 11200 & hernia & 3 & $3326 * *$ \\
\hline \multirow[t]{2}{*}{06000} & diseases of the nervous system & 1 & 239 \\
\hline & total death & 109 & $280 * *$ \\
\hline
\end{tabular}

$* *: \mathrm{p}<0.01, *: \mathrm{p}<0.5$.

Table 3. Details in SMR of malignant neoplasms in patients with spinal cord injury for a long time

\begin{tabular}{llcc}
\hline $\begin{array}{c}\text { ICD } \\
\text { code }\end{array}$ & $\begin{array}{c}\text { primary site of malignant neoplasms } \\
\text { based on ICD10 }\end{array}$ & $\begin{array}{c}\text { number of } \\
\text { death }\end{array}$ & SMR \\
\hline 02103 & stomach & 2 & 68 \\
02105 & colon & 3 & 176 \\
02106 & liver & 7 & $251^{*}$ \\
02108 & pancreas & 3 & 340 \\
02110 & trachea, bronchus and lung & 3 & 121 \\
02111 & skin & 3 & $6619^{* *}$ \\
02116 & bladder & 2 & $1482 * *$ \\
02120 & lymph and hematopoietic tissue & 3 & 359 \\
\hline
\end{tabular}

$* *: \mathrm{p}<0.01, *: \mathrm{p}<0.5$.

injury, it indicated especially lower in injury age groups over 40 -yr-old than the younger injury age groups. The result is consistent with the interpretations by Whiteneck ${ }^{11)}$. The difference might be caused by the aging process that occurred before injury which reduced the resilience of the individual to adapt to the changes brought by $\mathrm{SCI}^{19,20)}$. Regarding level of spinal cord injury, any difference was not detected. The reason is considered that almost all of SCI above T5 were incomplete paralysis, contrary SCI lower than T6 were mostly complete paralysis.

The mortality rate of persons with longstanding SCI seems to stem from secondary complications of SCI. The SMRs of septicemia resulting from decubitus complications and that of renal failure were extremely high, 6,827 and 3,739 respectively. Decubitus and renal failure have been decreasing, but they are still the most primary complications. Soden $^{21)}$ described high incidence of death caused by septicaemia, pneumonia, diseases of urinary system and suicide in long-term SCI. Furthermore decubitus and urinary tract complications might promote the carcinogenesis in each lesion. The SMR of cutaneous carcinoma developed from decubitus lesion was extremely high as 6,619 ( $p<0.01)$, also 
bladder carcinoma showed a high SMR at 1,482 ( $<<0.01)$. Thus cutaneous carcinoma and bladder carcinoma are considered to be complications of SCI. West ${ }^{22)}$ suggested the association between bladder malignancy and indwelling catheterization. Zeling ${ }^{23)}$ described the causes of deaths among SCI after $50 \mathrm{yr}$ follow-up, the top was cardiovascular, and the second was neoplastic diseases.

The second cause of death based on our research was circulatory diseases. The SMR of heart disease was 249 $(\mathrm{p}<0.01)$, and that of cerebrovascular disease was $301(p<0.01)$. Especially an increase of ischemic heart disease is anticipated in the future, because the frequency of hypertension and diabetes mellitus in SCI persons were higher than those of general population ( 2.5 times and 3 times higher, respectively)in our previous study ${ }^{24)}$. In the background, the prognosis of arteriosclerosis is influenced by the glucose intolerance. Glucose intolerance may be due in part to the atrophy in large mass of muscle and decrease of physical activity, both of which may promote insulin resistance and cause carbohydrate metabolism abnormality ${ }^{25-30)}$. With careful management of caloric intake and a physical fitness, an improvement in these complications is expected. However, there are no proper guidelines for nutritional assessment and physical fitness standards for paraplegics and tetraplegics, further studies should be devoted to these areas.

The third cause of death was external cause, suicide and accident. In accidental deaths, suspected cases for suicides were included. In this backgrounds, the metabolic changes of the central nervous system shown as a decrease of urinary tryptamine $^{31,32)}$ in SCI are suspected. One reason explaining depression on $\mathrm{SCI}$ is serious psychosocial difficulties inherent in a long-term SCI. Another reason is endocrinological and neurogenic change due to paralysis.

The problem of this survey is the use of the death statistics in 1995 alone as the standard population for the calculation of SMRs, while observed data were from 1965 to 1995 . The reason of this procedure is the adoption of ICD10 in this study. Precisely the calculation of SMRs by summation of deaths from 1965 to 1995 for standard population by using ICD9 should be done. This paper has a limited interpretation of the situation of death analysis. However, the trend of deaths in SCI persons is conspicuous and this result is to provide valuable information for the health control in SCI persons.

\section{References}

1) Guttman L (1947) Discussion on the treatment an prognosis of traumatic paraplegia. Proceedings of the Royal Society of Medicine 40, 219-25.

2) Lapides J, Diokno AC, Silber SJ, Lowe BS (1972) Clean intermittent self-catheterization in the treatment of urinary tract disease. J Urol 107, 458-61.

3) Murray K, Lewis P, Blannim J, Shepherd A (1984) Clean intermittent self-catheterization in the management of adult lower urinary tract dysfunction. Br J Urol 56, 37980.

4) Diokno AC, Sonda LP, Hollander JB, Lapides J (1983) Fate of patients started on clean intermittent selfcatheterization therapy 10 years ago. J Urol 129, 11202.

5) Hackler RH (1977) A 25-year prospective mortality study in the spinal cord Injured patient, comparison with the long-term living paraplegic. J Urol 117, 4868.

6) Le CT, Price M (1982) Survival from spinal cord injury. J Chron Dis 35, 487-92.

7) Geisler WO, Jousse AT, Wynne-Jones M, Breithaupt D (1983) Survival in traumatic spinal cord injury. Paraplegia 21, 364-73.

8) Sakai M, Yoshida I, Itoh F, Hattori Y, Itoh Y, Nakajima A (1983) Issues on aging in persons with spinal cord injuries, II. JJTOM 31, 659-63 (In Japanese).

9) Webb DR, Fitzpatrick JM, O'Flynn JD (1984) A 15year follow-up of 406 consecutive spinal cord injuries. Br J Urol 156, 616-7.

10) Yekutiel M,Brooks ME,Ohry A,Yarom J,Carel R (1989) The prevalence of hypertension, Ischemic heart disease and diabetes in traumatic spinal cord injured patients and amputees. Paraplegia 27, 58-62.

11) Whiteneck GG, Charlifue SW, Frankel HL, Fraser MH, Gardner BP, Gerhart KA, Krishnan KR, Menter RR, Nuseibeh I, Short DJ, Silver JR (1992) Mortality, morbidity, and psychosocial outcomes of persons spinal cord injured more than 20 years ago. Paraplegia 30, 617-30.

12) DeVivo MJ,Krause JS,Lammertse DP (1999) Recent trends in mortality and causes of death among persons with spinal cord injury. Arch Phys Med Rehabil 80, 1411-9.

13) El-Masri WS, Fellows G (1981) Bladder cancer after spinal cord injury. Paraplegia 19, 265-70.

14) World Health Organization (1995) International statistical classification of diseases and related health problems, 10th revision, WHO, Geneva.

15) Ministry of Health and Welfare (1995) The 18th life tables, Ministry of Health and Welfare, Japan. 
16) SAS/STAT User's guide (1988) SAS Institute Inc., California, US.

17) Ministry of Health and Welfare (1995) Vital statistics of 1995, Ministry of Health and Welfare, Japan.

18) Menter RR (1993) Spinal cord injury and aging, exploring the unknown. J Am Paraplegia Soc 16, 17989.

19) Ohry A, Shemesh Y, Roxin R (1983) Are chronic spinal cord injured patients (SCIP) prone to premature aging? Med Hypotheses 11, 467-9.

20) Kliesch WF, Cruse JM, Lewis RE, Bishop GR, Brackin B, Lampton JA (1996) Restoration of depressed immune function in spinal cord injury patients receiving rehabilitation therapy. Paraplegia 34, 82-90.

21) Soden RJ, Walsh J, Middleton JW, Craven ML, Rutkowski SB, Yeo JD (2000) Causes of death after spinal cord injury. Spinal Cord 38, 604-10.

22) West DA, Cummings JM, Longo WE, Virgo KS, Johnson FE, Parra RO (1999) Role of chronic catheterization in the development of bladder cancer in patients with spinal cord injury. Urology 53, 292-7.

23) Zeiling G, Dolev M, Weingarden H, Blumen N, Shemesh Y, Ohry A (2000) Long-term morbidity and mortality after spinal cord injury, 50 years of followup. Spinal Cord 38, 563-6.

24) Imai K, Kadowaki T, Aizawa Y, Fukutomi K (1996) Problems in health management for persons with spinal cord injuries in view of complication symptoms. J Clin Epidemiol 49, 505-10.
25) Duckworth WC, Jallepalli P, Solomon SS (1983) Glucose intolerance in spinal cord injury. Arch Phys Med Rehabil 64, 107-10.

26) Duckworth WC, Solomon S, Jallepalli P, Heckemeyer C, Finnern J, Powers A (1980) Glucose intolerance due to insulin resistance in patients with spinal cord injuries. Diabetes 29, 906-10.

27) Bauman WA, Spungen AM, Raza M, Rothstein B, Zhang R, Zhang Y, Tsuruta M, Shahidi R, Pierson RN, Wang J, Gordon SK (1992) Coronary artery disease, metabolic risk factors and latent disease in individuals with paraplegia. Mt Sinai J Med 59, 163-8.

28) Claus-Walker J, Halstead LS (1982) Metabolic and endocrine changes in spinal cord injury III. Arch Phys Med Rehabil 63, 628-31.

29) Bauman WA,Adkins RH,Spungen AM,Waters RL (1999) The effect of residual neurological deficit on oral glucose tolerance in persons with chronic spinal cord injury. Spinal Cord 37, 765-71.

30) Bauman WA, Spungen AM (2000) Metabolic changes in persons after spinal cord injury. Phys Med Rehabil Clin N Am 11, 109-40.

31) Garfinkel PE,Warsh JJ,Stancer HC (1979) Depression:new evidence in support of biological differentiation. Am J Psychiatry 136, 535-9.

32) Claus-Walker J,Halstead LS (1982) Metabolic and endocrine changes in spinal cord injury: III. Less quanta of sensory input plus bedrest and illness. Arch Phys Med Rehabil 63, 628-31. 